\title{
Sea turtle populations are overestimated worldwide from remigration intervals: correction for bias
}

\author{
Paolo Casale ${ }^{1, *}$, Simona A. Ceriani ${ }^{2,3}$ \\ ${ }^{1}$ Department of Biology, University of Pisa, Via A. Volta 6, 56126 Pisa, Italy \\ ${ }^{2}$ Fish and Wildlife Research Institute, Florida Fish and Wildlife Conservation Commission, Saint Petersburg, FL, USA \\ ${ }^{3}$ Department of Biology, University of Central Florida, Orlando, FL, USA
}

\begin{abstract}
Estimating population abundance is key for species of conservation concern. This is particularly challenging for marine animals, like sea turtles, with ocean-scale distribution and migratory nature. However, sea turtles lay clutches on land where they can be easily counted; thus, clutch number has always been the most common index of population abundance. A female typically lays $>1$ clutch per year and does not reproduce every year. Therefore, 2 conversion factors are needed to convert the number of egg clutches to the number of adult females: the number of clutches laid by a female in a nesting season and the fraction of adult females reproducing in a season, which is linked to the breeding periodicity. The effects of breeding periodicity, probability of detection and annual survival probability on the derived adult female abundance were investigated by simulating a virtual population of adult females over a $15 \mathrm{yr}$ beach monitoring period. The results indicate that current methods may greatly overestimate the abundance of sea turtle populations, especially in situations with a low detection probability, including temporary emigration. The factors involved and ways to minimize biases and errors are discussed, including a method which is easy to implement using existing datasets. A careful reassessment of current estimates of sea turtle abundance derived from nest counts and capture-mark-recapture data would be appropriate, and the potential error associated with such estimates should be considered when they are used in conservation status assessments.
\end{abstract}

KEY WORDS: Sea turtle $\cdot$ Remigration interval $\cdot$ Abundance $\cdot$ Breeding proportion $\cdot$ Mortality $\cdot$ Detection $\cdot$ Simulation

\section{INTRODUCTION}

Abundance is one of the most fundamental attributes that describe an animal population. It characterizes the ecological role of the population and possible metapopulation dynamics and helps contextualize other features, such as behavioral traits. Moreover, abundance is particularly crucial to define for species of conservation concern because a low abundance represents an inherent vulnerability to anthropogenic threats and because trends of abundance may

*Corresponding author: paolo.casale1@gmail.com highlight conservation problems or conservation successes. For instance, the IUCN Red List categorizes species and populations according to a risk of extinction assessed through several criteria, most of which are based on population abundance (IUCN 2017).

Sea turtles represent one of the taxa subjected to high attention by conservationists because their abundance has been diminished by anthropogenic activities to levels at which they may no longer fulfill their past ecological role (Jackson et al. 2001, Bjorndal \& Jackson 2003). Although direct exploitation for

(1) The authors 2020. Open Access under Creative Commons by Attribution Licence. Use, distribution and reproduction are unrestricted. Authors and original publication must be credited. 
turtle meat and eggs has been greatly reduced, several other anthropogenic threats are cause for increasing concern, such as incidental capture in fisheries (e.g. Wallace et al. 2013a), habitat destruction (e.g. Brock et al. 2009, Mazaris et al. 2009, Fuentes et al. 2016), pollution (e.g. D'Ilio et al. 2011, Casale et al. 2016, Lauritsen et al. 2017, Wallace et al. 2017) and climate change (e.g. Fuentes et al. 2011).

Estimating population abundance for marine animals is in general challenging, especially for migratory species, like sea turtles, with dispersed oceanscale distribution. Individuals belonging to the same population may frequent very distant foraging areas (e.g. Luschi et al. 2003, Benson et al. 2007, Ceriani et al. 2017), and a complete knowledge of the range of a population is difficult per se, making it difficult to estimate the abundance of a specific population at sea. However, sea turtles lay egg clutches on land and tend to return to the same breeding area over their lifetime. Therefore, breeding areas of a specific population are much easier to identify. On land, annual clutch counts represent the most common index of sea turtle population trends (e.g. National Marine Fisheries Service \& U.S. Fish Wildlife Service 2008, Witherington et al. 2009, Wallace et al. 2013b, Casale \& Tucker 2015, Mazaris et al. 2017). However, clutches are only indirectly linked to population abundance because the iteroparous females lay $>1$ clutch per breeding year, they do not reproduce every year (Miller 1997), adult females represent only a part of the adults, and adults are only a small part of the population. Therefore, conversion factors are needed to convert number of egg clutches to number of turtles. Although 3 conversion factors (clutch frequency, breeding proportion and sex ratio) are needed to estimate the number of adults, this is rarely attempted, for instance for specific criteria of the IUCN Red List Assessments (Wallace et al. 2013b, Casale \& Tucker 2015). It is more common to use 1 or 2 conversion factors to estimate the number of adult females nesting annually and the total number of adult females, respectively.

The first conversion factor to estimate the number of females reproducing in 1 season (annual nesting females [ANF]) is the number of clutches laid by a female in a nesting season (also known as clutch frequency). Although apparently easy to obtain, the partial fidelity of females to a nesting site and technical limitations of capture-mark-recapture (CMR) through flipper tagging often underestimated this factor, until satellite tracking (Tucker 2010, Weber et al. 2013, Esteban et al. 2017) and more recently gene- tic fingerprinting (Shamblin et al. 2017) studies were introduced.

The second conversion factor, required to convert ANF to total females (TF), is the breeding proportion (BP), i.e. the fraction ANF/TF of adult females that reproduce in a season. This parameter is much more problematic to estimate because TF is both what would be needed to calculate BP and the unknown target parameter. The $\mathrm{BP}$ is the consequence of iteroparous turtles that do not breed annually, with a longer average remigration interval (RI, the number of years between consecutive breeding seasons) causing a lower BP. Many studies have used observed RI as the reciprocal of BP to estimate adult female abundance (e.g. Spotila et al. 1996, Richardson et al. 1999, Beggs et al. 2007, Richards et al. 2011, Marco et al. 2012, Bellini et al. 2013, Casale \& Heppell 2016, Gallaway et al. 2016, Warden et al. 2017) or to model population dynamics (e.g. Chaloupka 2002, 2003, Heppell et al. 2005, Troëng \& Chaloupka 2007, Piacenza et al. 2016, 2017). Other studies derived RI and/or BP from transition probabilities between breeding and non-breeding states estimated, among other parameters, through CMR models (e.g. Phillips et al. 2014, García-Cruz et al. 2015, Piacenza et al. 2016), although the conversion equations were not consistent among these studies. Both the direct (observed RI) and modeling approaches need the same CMR data.

Obtaining adequate CMR data is challenging because it requires identifying individual females across nesting seasons, which is commonly attained by flipper tagging (e.g. Broderick et al. 2003, Ehrhart et al. 2014, Hamilton et al. 2015, Garner et al. 2017) with great limitations. For instance, low detection capacity by the monitoring teams can produce longer observed remigration intervals caused by missing encounters. Tracking individual females for several years (e.g. through satellite telemetry) is still technically unfeasible, and the rare positive cases (e.g. Zbinden et al. 2008, Marcovaldi et al. 2010, Hawkes et al. 2011, Ceriani et al. 2012, Mingozzi et al. 2016) are too few to be helpful. CMR based on genetic fingerprinting (Shamblin et al. 2017) could theoretically provide data on RI, but such an approach is feasible only for small populations or at small geographic scales. Mortality is another parameter that can affect the observed RI, and ways to correct such biases have seldom been attempted (e.g. Richards et al. 2011). This study aims to assess how the different parameters involved can affect the estimation of adult female abundance from remigration intervals and to provide indications of how to minimize potential errors. 


\section{MATERIALS AND METHODS}

\subsection{Proportion of annual breeding females}

Adult female turtles do not breed every year. The relationship between the total number of adult females in a population (TF) and the number of females nesting in a given year (annual nesting females [ANF]) is given by their ratio, or breeding proportion (BP):

$$
\mathrm{BP}=\frac{\mathrm{ANF}}{\mathrm{TF}}
$$

Therefore, if BP is known, it can be used to convert ANF (observed) to TF (unknown), assuming a stable population:

$$
\mathrm{TF}=\frac{\mathrm{ANF}}{\mathrm{BP}}
$$

BP can be estimated from capture-mark-recapture histories of females nesting in different years, with the interval between 2 consecutive nesting seasons called the remigration interval (RI). All the following simulations and analyses were performed in R v.3.5.1 (R Development Core Team 2018).

\subsection{Simulated breeding female assemblage}

To test different ways of estimating BP, we created a virtual assemblage of TF individuals (total adult females) with a given mean remigration interval $(M)$, through the following procedure. We assumed a Poisson distribution of RIs with mean $M$ and calculated the number of cases with RI values ranging from 1 to $10 \mathrm{yr}$ out of a total of 1000 cases. From this sample of 1000 values, a maximum of 25 random values of RI were extracted and used to create the reproductive history of an individual adult female along $25 \mathrm{yr}$, i.e. in which year she nested. This process was repeated for each of the TF individual turtles of the virtual assemblage. Then the first $10 \mathrm{yr}$ were discarded to remove possible effects of the starting year, and the remaining 15 yr represented the observation window of a virtual capture-mark-recapture program. From this simulation, the 'true' ANF was calculated as the average number of turtles breeding per year. Then, the effects of probability of detection and of annual survival probability on the 'observed' results of a virtual CMR program were simulated as follows.

A probability of detection $p$ was applied to all the breeding events, and each breeding turtle was assigned to an observed/not observed status through a random binomial function. From these simulated breeding observations, the average number of nesting females observed per year $\left(\mathrm{ANF}_{\text {obs }}\right)$ was calculated. Assuming a stable population, the observed probability of detection was calculated as:

$$
p_{\text {obs }}=\frac{\mathrm{ANF}_{\mathrm{obs}}}{\mathrm{ANF}}
$$

A survival probability $S^{t}$ was calculated for each time a turtle was re-encountered after being observed (and tagged) the first time (where $S$ is the annual survival probability and $t$ is the interval since the first tagging) and converted into a dead/alive status through a random binomial function. If a turtle was marked as dead in $1 \mathrm{yr}$, it remained in that status for the rest of the years. In other words, although all turtles are subjected to mortality, in a stable population dead turtles are replaced while tagged turtles are not (they are specific individuals that are monitored along the years). For this reason, $S$ is applied only to tagged animals.

In this way, for each turtle, we obtained a simulated CMR history resulting from a combination of $M, p$ and $S$. In such a formulation, $S$ can be considered to include also tag loss, and $p$ can include temporary emigration (temporary unavailability). Simulations were run with a range of values of $M$ (13 values ranging from 1.6 to $4 \mathrm{yr}$ with interval 0.2$), S$ (7 values ranging from 0.70 to 1.00 with interval 0.05$), p(10$ values ranging from 0.1 to 1.0 with interval 0.1 ) and TF (7 values: 25, 50, 100, 150, 200, 250, 1000 turtles).

\subsection{BP estimation}

BP was estimated through 4 different methods.

The first method ('REM', based on the mean remigration interval) is the most common one and estimates BP as the reciprocal of the average RI:

$$
\mathrm{BP}=\frac{1}{\overline{\mathrm{RI}}}
$$

Remigration intervals were obtained from the individual CMR histories, potentially including multiple remigration intervals for each turtle. The average RI was calculated from all RIs (including multiple RIs from the same individual turtle).

The second method ('MSLR') was based on a MultiState Live Recapture model, implemented by the Rmark package for R (R Development Core Team 2018). The model included 2 possible states for any given year: an observable state (breeding) and an unobservable state (not breeding). The model esti- 
mates 4 direct parameters: adult female survival rate $(S)$, probability of detection $(p)$, probability of moving from breeding to non-breeding state $\left(\psi^{\mathrm{B} \rightarrow \mathrm{NB}}\right)$ and probability of moving from non-breeding to breeding state $\left(\psi^{\mathrm{NB} \rightarrow \mathrm{B}}\right)$. All parameters were set as constant across years. Since in a stable population:

$$
\mathrm{ANF}=\mathrm{ANF} \times\left(1-\psi^{\mathrm{B} \rightarrow \mathrm{NB}}\right)+\mathrm{NBF} \times \psi^{\mathrm{NB} \rightarrow \mathrm{B}}
$$

and

$$
\mathrm{TF}=\mathrm{ANF}+\mathrm{NBF}
$$

where NBF is the number of non-breeding females per year, then:

$$
\begin{aligned}
\mathrm{BP} & =\frac{\mathrm{ANF}}{\mathrm{TF}} \\
& =\frac{\operatorname{ANF}\left(1-\psi^{\mathrm{B} \rightarrow \mathrm{NB}}\right)+(\mathrm{TF}-\mathrm{ANF}) \psi^{\mathrm{NB} \rightarrow \mathrm{B}}}{\mathrm{TF}} \\
& =\frac{\psi^{\mathrm{NB} \rightarrow \mathrm{B}}}{\psi^{\mathrm{B} \rightarrow \mathrm{NB}}+\psi^{\mathrm{NB} \rightarrow \mathrm{B}}}
\end{aligned}
$$

The third method ('MSLR $p$-corr') was a variant of MSLR in which $p$ was fixed to a value equal to $p_{\text {obs }}$. This represents the case when the probability of detection can be estimated from additional data. For instance, an approximate estimation of $p$ ( $\left.p_{\text {est }}\right)$ can be obtained as:

$$
p_{\text {est }}=1-(1-e)^{C}
$$

where $C$ is the number of clutches a female lays in a nesting season (also known as clutch frequency), and $e$ is the probability of observing a nesting event. In other words, the probability of encountering an individual turtle at least 1 time during a nesting season increases with the number of times the turtle comes ashore to lay eggs. In turn, e can be estimated from the total number of clutches laid in a nesting season $\left(C_{\text {tot }}\right)$ and the number of clutches where the turtle was encountered $\left(C_{\text {obs }}\right)$ :

$$
e=\frac{C_{\text {obs }}}{C_{\text {tot }}}
$$

The fourth method ('REM- $t$ ', based on the mean remigration interval calculated from a conditionally truncated distribution) assumes that long remigration intervals are an artifact caused by low detection probability and implements the simple approach of removing the presumed artifacts from the dataset. This method is a variant of REM, where a correction was applied in case of a highly right-skewed distribution, which can be an indication of overestimated (artifact) RI values. What to consider a highly rightskewed distribution and where to truncate the distribution are 2 key parameters that were empirically investigated through a series of trials, and we pro- pose the following method. The first (lowest) mode of the frequency distribution of RIs is identified and the number of values of 2 parts of the dataset is calculated: (A) the number of RIs $\leq$ mode +2 and (B) the number of RIs $>$ mode+ 2 (B). If $\mathrm{B} / \mathrm{A} \geq 0.1$ (denoting a right-skewed distribution), then the mean RI is calculated only on the A values; otherwise, the mean RI is calculated on the entire dataset.

\subsection{Correction for mortality}

We simulated the case when an estimated $S$ is available and correction for mortality can be implemented. Two scenarios where simulated, with a correct and with a wrong estimation of $S$. For the methods MSLR and MSLR $p$-corr, $S$ was given as a fixed parameter in the model. For the methods REM and REM-t, the observed frequency distribution of remigration intervals (RIobs) was converted into an $S$-corrected frequency distribution by reconstructing the number of RIs (RIcorr) that would have been observed if the turtle had not died, for each remigration interval $i$ :

$$
\mathrm{RICorr}_{i}=\frac{\operatorname{RIobs}_{i}}{S^{i}}
$$

\section{RESULTS}

A total of 910 simulations of a virtual assemblage of 1000 adult females were performed, with $M$ ranging from 1.6 to 4.0 (n = 13 values), $S$ ranging from 0.70 to 1.00 ( $\mathrm{n}=7$ values) and $p$ ranging from 0.1 to $1.0(\mathrm{n}=$ 10 values) (see Table S1 in the Supplement at www. int-res.com/articles/suppl/n041p141_supp.pdf). The effects of $S$ and $p$ on the observed remigration intervals (RI) are shown in Fig. 1 with the example of $M=$ 2.6. Low $S$ values reduced the number of long RIs, with the result of underestimating the observed mean RI. On the contrary, low $p$ values increased the number of long RIs, with the result of overestimating the observed mean RI.

When the 4 combinations of realistic low and high values of $S(0.70$ and 0.95 ; see a review by Casale et al. 2015) and $p$ (0.1 and 1) are used in simulations with the 13 different values of $M$ considered, the results indicate a stronger effect of $p$ than $S$ on the estimation of the adult female assemblage size by the 2 methods currently used (the reciprocal of RI and CMR models, here represented by REM and MSLR, respectively) and that a low $S$ can only partially compensate for a low $p$ (Fig. 2). In the range of $M$ considered, with $S=0.95$ and $p=0.1$ the error ranged from 

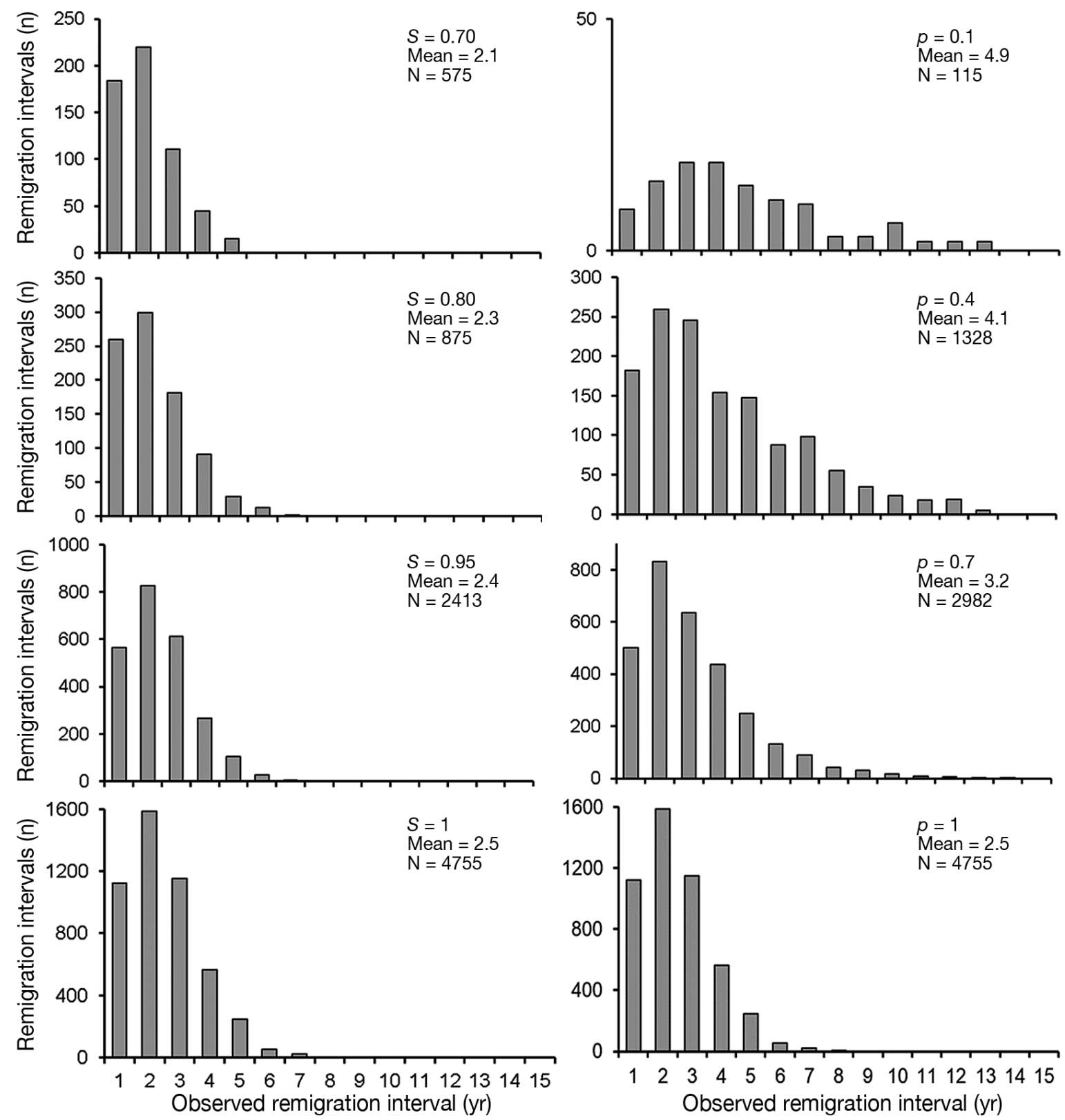

Fig. 1. Frequency distribution of turtle female remigration intervals (RI) observed from different simulations of a virtual turtle assemblage of 1000 adult females and mean RI $=2.6$ yr as an example. Different scenarios are shown with (left panels) fixed detection probability $(p)=1$ and annual survival probability $(S)$ ranging from 0.70 to 1 and (right panels) fixed survival ( $S=1$ ) with $p$ ranging from 0.1 to 1 . Resulting mean RI and number of observed RIs (N) are shown

28 to $188 \%$ (median $=71 \%$; IQ range: $47-120)$ for method REM and from -27 to $1133 \%$ (median = $812 \%$; IQ range: $13-858 \%$ ) for method MSLR. The 2 methods with corrections (respectively REM-t and MSLR $p$-corr) greatly reduced the error (Fig. 2). Over a range of $S$ and $p$ values, the overall effect was an overestimation of adult female assemblage size, with increasing errors at lower and higher mean RI for the REM and MSLR methods, respectively (Fig. 3). Also in this case, the 2 methods with corrections (respectively REM-t and MSLR $p$-corr) greatly reduced and balanced the errors at different $M$ values (Fig. 3).

Of the 4 methods to calculate BP to estimate the adult female assemblage size, REM-t showed the best performance over a variety of $M, S$, and $p$ (median: $-10.8 \%$; IQ range: $-18.2-2.4 \%$; range: $-48.8-48.9 \%$; $\mathrm{n}=768$ ), followed by REM, MSLR $p$-corr and MSLR (Fig. 4). Thanks to the inclusion of additional informa- 


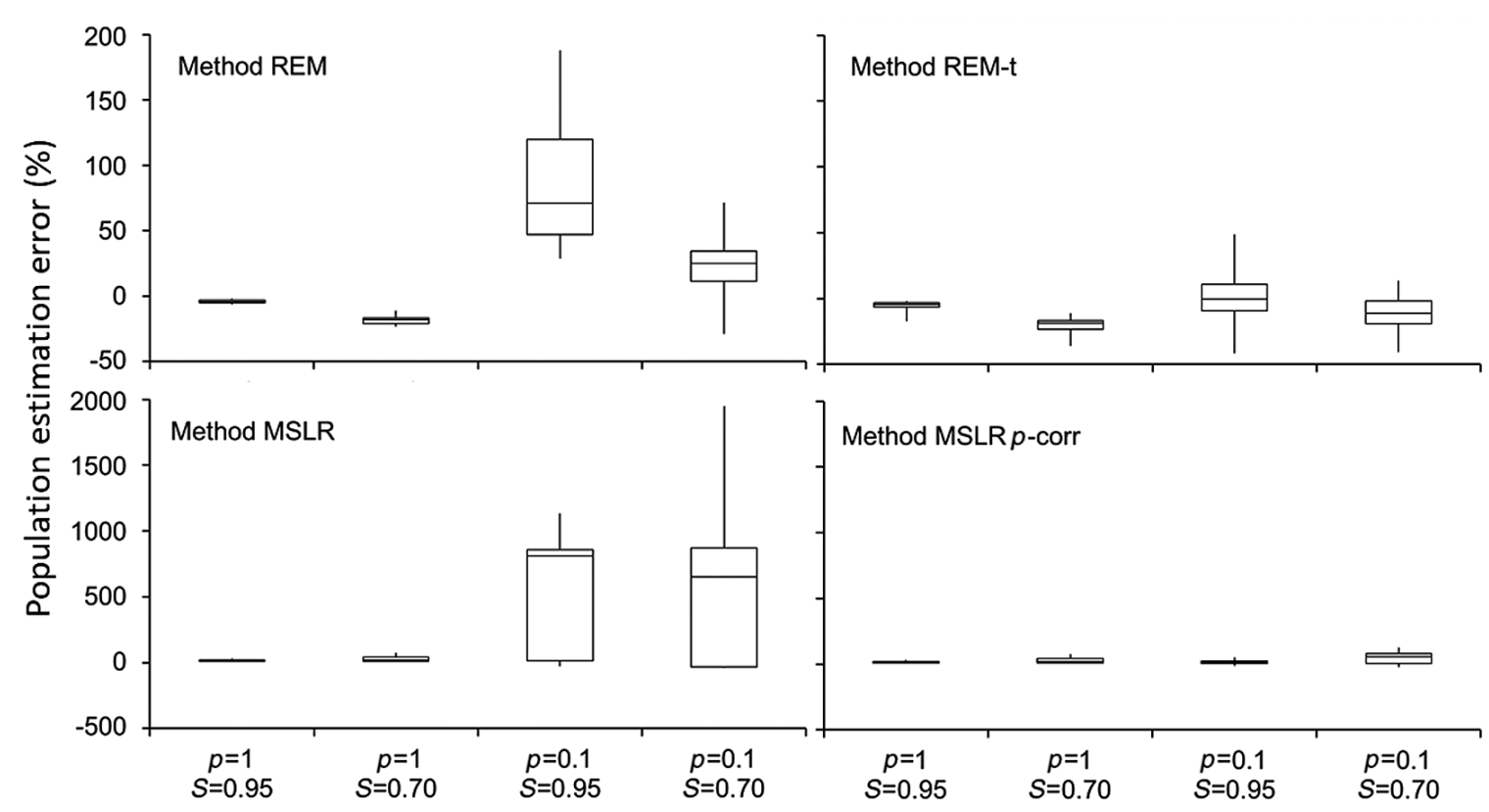

Fig. 2. Errors (\%) of sea turtle adult female assemblage size estimated ([estimated - real]/real) from a virtual assemblage of 1000 adult females with mean remigration interval ranging from 1.6 to $4 \mathrm{yr}$ (interval $0.2 ; \mathrm{n}=13$ ). Distributions of the resulting 13 error values are shown as a box-plot (median, quartiles 1 and 3, and min-max) for each of the 4 combinations of 2 values of $S$ and 2 values of $p$. Four methods to derive the breeding proportion are compared: mean remigration interval (REM), mean remigration interval calculated from a conditionally truncated distribution (REM-t, see Section 2.3), multistate live recapture

model (MSLR), and MSLR corrected with fixed $p$ estimated from simulation results (MSLR $p$-corr; see Section 2.3)

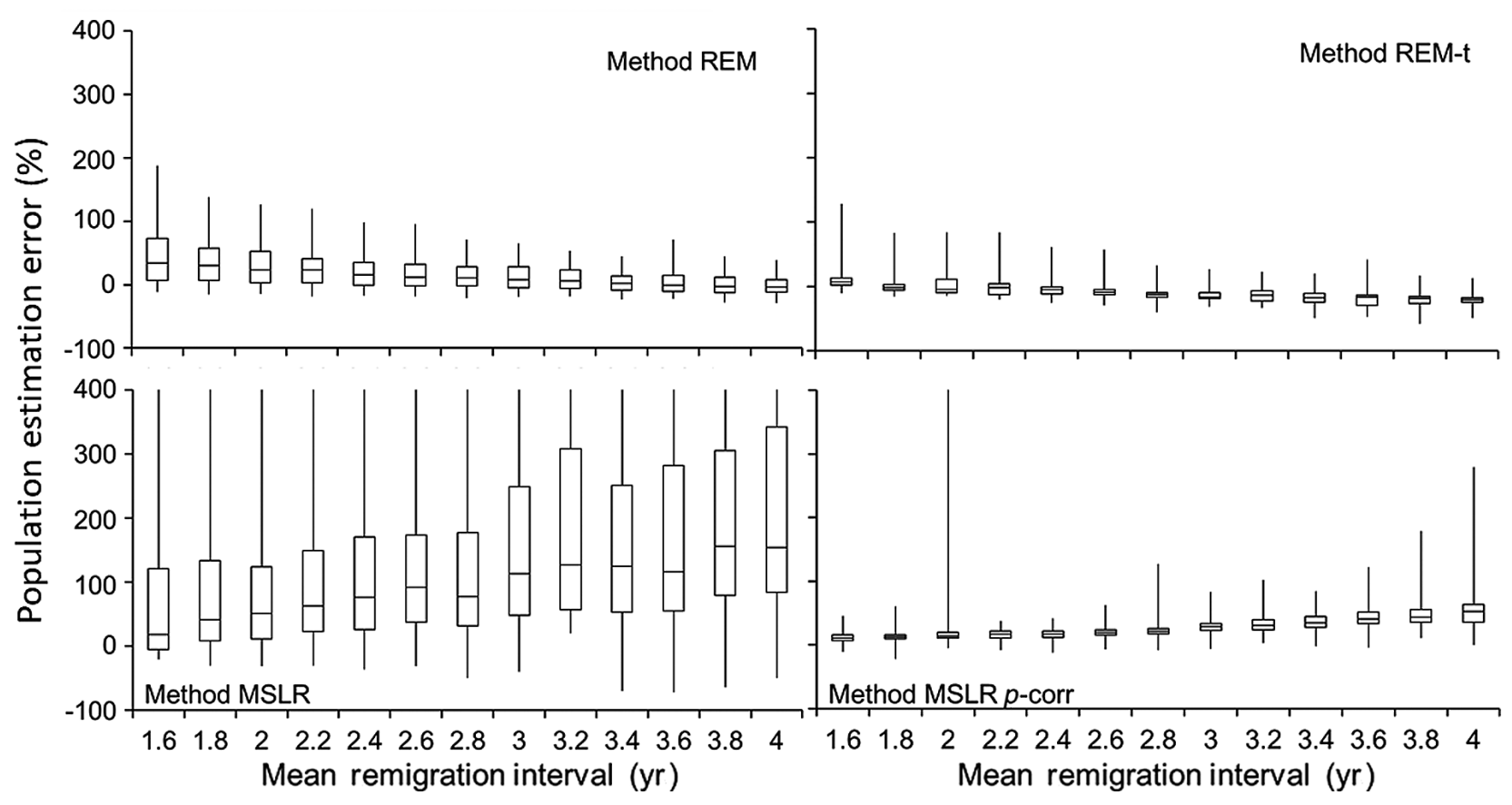

Fig. 3. Errors (\%) of sea turtle adult female assemblage size estimated from a virtual assemblage of 1000 adult females with $S$ ranging from 0.7 to 0.95 (interval $0.5 ; \mathrm{n}=6$ ) and $p$ ranging from 0.1 to 1 (interval $0.1 ; \mathrm{n}=10$ ). Distributions of the resulting 60 error values are shown as a box-plot for each of 13 values of given mean remigration interval. See Fig. 2 for details. Upper whiskers of MSLR and one of MSLR $p$-corr are truncated for display purposes 


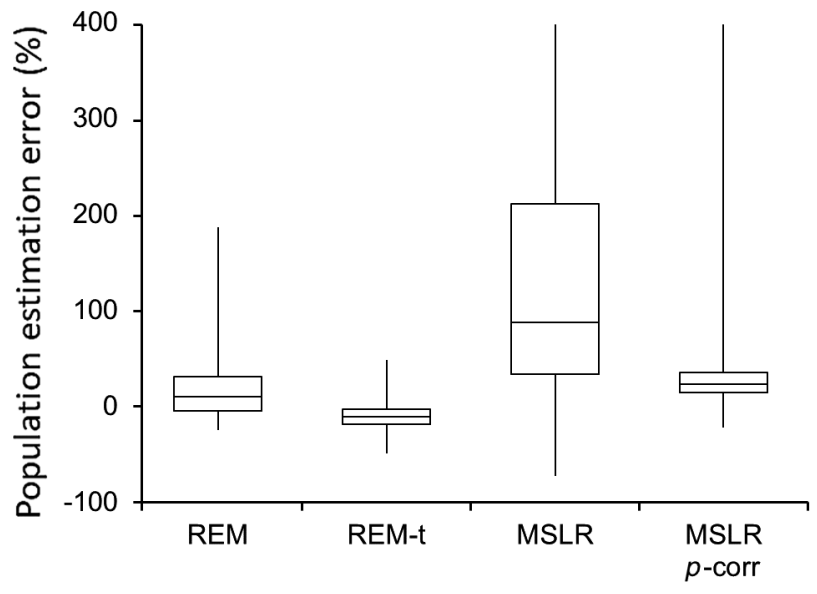

Fig. 4. Errors (\%) of sea turtle adult female assemblage size estimated from a virtual assemblage of 1000 adult females with mean remigration interval ranging from 1.6 to 4 yr (interval $0.2 ; \mathrm{n}=13$ ), $S$ ranging from 0.7 to 0.95 (interval $0.5 ; \mathrm{n}=$ 6 ) and $p$ ranging from 0.1 to 1 (interval $0.1 ; \mathrm{n}=10$ ). Of the resulting 780 error values, only those derived from a minimum of 20 remigration intervals were considered $(n=768)$, and their distribution is shown as a box-plot. See Fig. 2 for details. The latter 2 cases had a few very high values, and the upper whiskers are truncated for display purposes tion ( $p_{\text {; }}$ virtually obtained from other sources, see Section 2), MSLR $p$-corr greatly improved the performance of MSLR in terms of IQ range, but very high values were still produced. The correction approach undertaken by REM-t removed the bias and narrowed both IQ and total ranges of errors in comparison to REM.

Simulations with a range of virtual assemblage sizes from 25 to 1000 adult females show that errors increase at low assemblage sizes, with the possible exception of MSLR (see Figs. S1 \& S2). However, this was because a low number of RIs are observed from smaller assemblages. When this effect was removed by calculating BP only from data sets with at least 20 RIs, the performance was similar at any assemblage size (Fig. S3), indicating that assemblage size has no effect per se and that a sample size of $20 \mathrm{RI}$ is enough to estimate BP, at least with the REM-t method.

Correction of low $S$ with the real $S$ value worsened the performance of all methods except MSLR $p$-corr. The latter had a good performance, similar to REM-t, although moderately high-biased (Fig. 5). When $S$ was corrected with an erroneous lower $S$ value, all

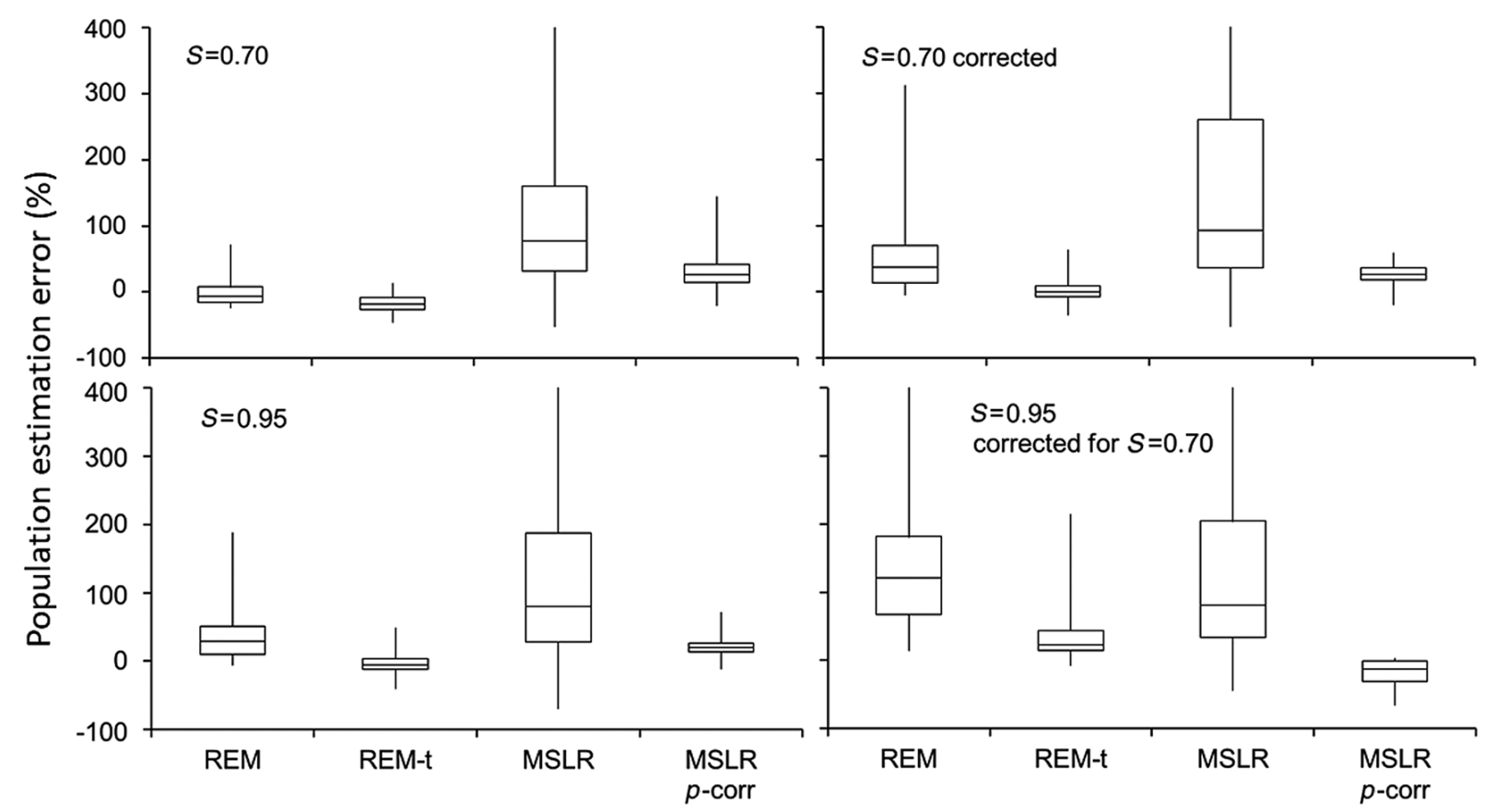

Fig. 5. Errors (\%) of sea turtle adult female assemblage size estimated from a virtual assemblage of 1000 adult females with mean remigration interval ranging from 1.6 to $4 \mathrm{yr}$ (interval $0.2 ; \mathrm{n}=13$ ), $p$ ranging from 0.1 to 1 (interval $0.1 ; \mathrm{n}=10$ ) and $S$ ranging from 0.7 to 0.95 (interval $0.5 ; \mathrm{n}=6$ ). Results for $S$ of 0.70 and 0.95 (on the left) are compared with the same $S$ values with a correction for $S=0.70$ (on the right), which represents a case of correction with a correct estimate of $S$ in the top-right panel and a case of correction with an erroneous estimate of $S$ in the bottom-right panel. Of the resulting 130 error values, only those derived from minimum 20 remigration intervals were considered. This condition was met in all 130 cases of the simulations ' $S=0.95$ ' and ' $S=0.95$ corrected for $S=0.70$ ', while 124 and 129 values were considered for the simulations ' $S=0.70$ ' and ' $S=0.70$ corrected', respectively. See Fig. 2 for details 
methods (and especially REM) provided worse results (Fig. 5). It should be noted that the correction approach for methods REM and REM-t (Eq. 10) successfully provided the true mean RI when $p=1$ (simulations with $S=0.70$ and $M$ ranging from 1.6 to $4 \mathrm{yr}_{\text {; }}$ mean error $=0.008 ; \mathrm{n}=13$ ).

\section{DISCUSSION}

This study provides information and methods that can contribute to future assessments of abundance and conservation status of sea turtle populations as well as to the re-assessment of previous estimates. Sea turtle population abundance (at least that of adult females) is currently derived from nest counts, which are converted into number of individuals through capture-mark-recapture data (i.e. clutch frequency and 'remigration intervals' or through more complex modeling). The present study strongly indicates that this conversion bears the risk of producing estimates very different from the real abundance. Although this risk may vary with the method, it cannot be totally eliminated, and this should be carefully considered when using population abundance estimations to derive the conservation status of populations.

The results show that mortality and detection probability may have important effects in estimating abundance. A low apparent survival probability may be caused both by a real low survivorship or by tag loss (see Pfaller et al. 2019 for a review of tag loss estimates wordwide). In both cases, the turtle cannot be detected anymore. A method to reduce missed identification due to tag loss is the subcutaneous application of passive integrated transponders (PIT) tags (Balazs 1999). However, PIT tags are expensive (compared to regular external flipper tags) and require the use of a PIT tag scanner, limiting their systematic use in many locations worldwide.

Detection probability is a particularly problematic parameter because it showed the greatest effect on population abundance estimate. With lower detection, fewer nesting events are observed, leading to incomplete individual nesting history and longer observed remigration intervals. A low detection probability may be caused by 2 different factors. A limited spatial or temporal capacity of the monitoring program would not detect all the turtles on the nesting beach (e.g. Pfaller et al. 2013). Another factor might be a limited site fidelity of turtles to the monitored beach across years. Turtles may not be detected in their breeding year because they laid clutches somewhere else; in another year, if they return to the original nesting beach where they were tagged and are encountered again, their remigration interval would appear longer than the reality. Naturally, long remigration intervals can only be reported by long-term monitoring projects. Therefore, although long-term projects are the most valuable ones in many respects, they also bear the highest risk of observing biased (long) remigration intervals (e.g. Ehrhart et al. 2014) and of producing biased (high) population abundance estimates. A good detection probability can be achieved only with a complete and regular monitoring of a nesting site with low-moderate nesting activity. For instance, we estimated (Eq. 8) that a $p$ close to 1 was achieved, at least in certain years, at sites with intensive monitoring effort and just tens or a few hundreds of nesting events per year (e.g. Broderick et al. 2002, Bellini et al. 2013). In such cases, basically all turtles nesting in a certain season were encountered at least 1 time. Where, on the contrary, only partial monitoring is possible and/or a high number of clutches is laid annually, making it impossible to observe a good proportion of nesting activity, the detection probability can be very low. For instance, we estimated (Eq. 8) $p=0.06$ at the Archie Carr National Wildlife Refuge (central east coast of Florida, USA) in the period 1982 to 2012, where an average of 11556 clutches were laid annually (Ehrhart et al. 2014).

Given that complete monitoring is rare and population abundance at regional management unit (Wallace et al. 2010) or species is driven by major nesting sites with high numbers of clutches per year, it is likely that population abundance assessments are based on datasets affected by imperfect detection. Therefore, the present results suggest that current estimates of turtle populations, mostly derived through method REM, may be overestimated, even by a factor of 2 . Moreover, studies that adjusted data (remigration intervals) for mortality but not for detection (e.g. Richards et al. 2011) probably produced even greater overestimations. Since estimating $S$ is difficult and estimates can be wrong, the small benefits of a good correction of $S$ are not worth the great errors caused by a wrong correction. It is worth noting that even greater errors may be produced by more sophisticated CMR models (here represented by the MSLR method), which need to estimate at least 4 unknown parameters simultaneously. Results show incorrect estimates of all 4 parameters by MSLR in most simulations. As expected, fixing 1 parameter $(p)$ with values close to real ones greatly improved the estimates of the other 3 parameters and fixing a second parameter $(S)$ produced a further im- 
provement, although slight. The decreased performance of CMR models in simulations with low detection probability was also reported by Troëng \& Chaloupka (2007). In principle, robust design models using captures in secondary periods (i.e. within the same nesting season) should better estimate detection probability. However, such analyses may not be effective in some cases (e.g. Hamilton et al. 2015), require substantial increases in the number of parameters of the model and, obviously, cannot be applied if data about intra-season re-encounters are not available.

With the understanding that the population abundance of marine animals like sea turtles is inherently elusive and that any method bears a risk of error, we propose a method (method REM-t, mean remigration interval calculated from a conditionally truncated

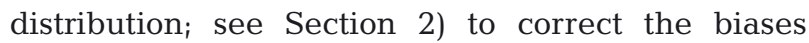
potentially produced by the most common method currently used (method REM). In the simulations, REM-t performed better than the methods except in some cases where the result was similar to that of the CMR $p$-corr method. REM-t is a simple and practical method, easy to implement in future studies as well as on existing datasets that are available at least in the form of frequency distribution of remigration intervals. It basically consists of right-censoring the dataset if there is evidence of a high right-skewness, which suggests the presence of artifact values due to a low detection probability. This method was robust in a variety of simulations with wide ranges of values of the main parameters involved, such as mean remigration interval $(M)$, detection probability $(p)$ and annual survival probability $(S)$. It performed well also in case of correction for $S$ and even minimized the error due to correction with a wrong $S$ value.

It is important to remember that converting annual nesting females to total females by means of a conversion factor in the form of a breeding proportion (independently of how breeding proportion is estimated) assumes that the population is stable. One single breeding proportion value is estimated from the entire CMR study period and is commonly applied to an average number of annual nesting females. The simulations presented here were based on the same assumption. Naturally, even higher risks of errors may occur when estimating the abundance of a non-stable population, making corrections more difficult.

There is growing evidence, from the present and other studies (e.g. Tucker 2010, Pfaller et al. 2013, Weber et al. 2013, Esteban et al. 2017, Ceriani et al. 2019), of the risks associated with deriving sea turtle demographic parameters from nesting activity. Demographic parameters such as population abundance (at least of adult females) and annual survival probability are needed for proper management of sea turtles and deserve a careful understanding and a proper analysis of data. Obtaining suitable data is not a simple task. A complete seasonal and spatial coverage of the nesting activity in a site can increase the detection of clutches and of individual females. A high and constant effort across years can increase detection probability and minimize temporal biases. Researchers should restrain from estimating demographic parameters if the quality of data is questionable.

In summary, we recommend: (1) using only datasets with at least 20 remigration intervals (including multiple values from the same turtle), no matter the population size, (2) avoiding correction for $S$, (3) interpreting with caution the results of CMR models, since very large errors are possible, and in these models (4) fixing the detection probability parameter with values obtained by other sources whenever possible, (5) applying the correction method described here (REM-t; see Section 2) in place of the commonly used REM and in addition to CMR models, enhancing the value of nesting monitoring programs for abundance studies by (6) estimating the detection probability (see Eq. 8) and attempting to increase it if it is low, (7) always double tagging (and possibly applying PIT tags) and (8) having a consistent and complete spatio-temporal coverage of the nesting activity in a nesting area.

A recent re-evaluation of clutch frequency estimates (the other conversion factor relating clutches to females, see Section 1) found that the traditional method based on CMR could overestimate turtle abundance by a factor of 2 in cases of low detection probability (Tucker 2010, Weber et al. 2013, Esteban et al. 2017). Therefore, the combination of the 2 conversion factors (clutch frequency and remigration interval) obtained by traditional methods could have produced estimates of adult female abundance much higher than the reality. Thus, a general reassessment for populations should be deemed urgent to understand their real conservation status. The availability of new or improved methods to estimate clutch frequency and breeding proportion should encourage undertaking the ambitious task of estimating adult female abundance of as many sea turtle populations as possible. Reliable data on these 2 parameters, which are important for several other aspects, are still very limited, and their variation in time and among different populations should be assessed to improve our knowledge of the populations and to quantify the associated uncertainty. 
Acknowledgements. The study was partially funded by the Marine Vertebrate Research Institute (Rome, Italy). We thank 4 anonymous reviewers for their comments on a previous version of the manuscript.

\section{LITERATURE CITED}

Balazs GH (1999) Factors to consider in the tagging of sea turtles. In: Eckert KL, Bjorndal KA, Abreu-Grobois FA, Donnelly M (eds) Research and management techniques for the conservation of sea turtles. IUCN/SSC Marine Turtle Specialist Group Publication No. 4, Gland, p 101-109

Beggs JA, Horrocks JA, Krueger BH (2007) Increase in hawksbill sea turtle Eretmochelys imbricata nesting in Barbados, West Indies. Endang Species Res 3:159-168

* Bellini C, Santos AJB, Grossman A, Marcovaldi MA, Barata PCR (2013) Green turtle (Chelonia mydas) nesting on Atol das Rocas, north-eastern Brazil, 1990-2008. J Mar Biol Assoc UK 93:1117-1132

Benson SR, Dutton PH, Hitipeuw C, Samber B, Bakarbessy J, Parker D (2007) Post-nesting migrations of leatherback turtles (Dermochelys coriacea) from Jamursba-Medi, Bird's Head Peninsula, Indonesia. Chelonian Conserv Biol 6:150-154

Bjorndal KA, Jackson JBC (2003) Roles of sea turtles in marine ecosystems: reconstructing the past. In: Lutz PL, Musick JA, Wyneken J (eds) The biology of sea turtles, Vol II. CRC Press, Boca Raton, FL, p 259-273

Brock KA, Reece JS, Ehrhart LM (2009) The effects of artificial beach nourishment on marine turtles: differences between loggerhead and green turtles. Restor Ecol 17: 297-307

Broderick AC, Glen F, Godley BJ, Hays GC (2002) Estimating the number of green and loggerhead turtles nesting annually in the Mediterranean. Oryx 36:227-235

* Broderick AC, Glen F, Godley BJ, Hays GC (2003) Variation in reproductive output of marine turtles. J Exp Mar Biol Ecol 288:95-109

Casale P, Heppell SS (2016) How much sea turtle bycatch is too much? A stationary age distribution model for simulating population abundance and potential biological removal in the Mediterranean. Endang Species Res 29: 239-254

Casale P, Tucker AD (2015) Caretta caretta. IUCN Red List of Threatened Species, v. 2016.2. www.iucnredlist.org (accessed 23 September 2016)

Casale P, Freggi D, Furii G, Vallini C and others (2015) Annual survival probabilities of juvenile loggerhead sea turtles indicate high anthropogenic impact on Mediterranean populations. Aquat Conserv 25:690-700

Casale P, Freggi D, Paduano V, Oliverio M (2016) Biases and best approaches for assessing debris ingestion in sea turtles, with a case study in the Mediterranean. Mar Pollut Bull 110:238-249

Ceriani SA, Roth JD, Evans DR, Weishampel JF, Ehrhart LM (2012) Inferring foraging areas of nesting loggerhead turtles using satellite telemetry and stable isotopes. PLOS ONE 7:345335

* Ceriani SA, Weishampel JF, Ehrhart LM, Mansfield KL, Wunder MB (2017) Foraging and recruitment hotspot dynamics for the largest Atlantic loggerhead turtle rookery. Sci Rep 7:16894

Ceriani SA, Casale P, Brost M, Leone EH, Witherington BE (2019) Conservation implications of sea turtle nesting trends: elusive recovery of a globally important loggerhead population. Ecosphere 10:e02936

* Chaloupka M (2002) Stochastic simulation modelling of southern Great Barrier Reef green turtle population dynamics. Ecol Modell 148:79-109

Chaloupka M (2003) Stochastic simulation modeling of loggerhead population dynamics given exposure to competing mortality risks in the Western South Pacific. In: Bolten $\mathrm{AB}$, Witherington $\mathrm{BE}$ (eds) Loggerhead sea turtles. Smithsonian Books, Washington, DC, p 274-294

* D'llio S, Mattei D, Blasi MF, Alimonti A, Bogialli S (2011) The occurrence of chemical elements and POPs in loggerhead turtles (Caretta caretta): an overview. Mar Pollut Bull 62:1606-1615

* Ehrhart L, Redfoot W, Bagley D, Mansfield K (2014) Longterm trends in loggerhead (Caretta caretta) nesting and reproductive success at an important western Atlantic rookery. Chelonian Conserv Biol 13:173-181

Esteban N, Mortimer JA, Hays GC (2017) How numbers of nesting sea turtles can be overestimated by nearly a factor of two. Proc R Soc B 284:2581

* Fuentes MMPB, Limpus CJ, Hamann M (2011) Vulnerability of sea turtle nesting grounds to climate change. Glob Change Biol 17:140-153

Fuentes MMPB, Gredzens C, Bateman BL, Boettcher R and others (2016) Conservation hotspots for marine turtle nesting in the United States based on coastal development. Ecol Appl 26:2708-2719

*Gallaway BJ, Gazey WJ, Caillouet CW Jr, Plotkin PT and others (2016) Development of a Kemp's ridley sea turtle stock assessment model. Gulf Mex Sci 33:138-157

* García-Cruz MA, Lampo M, Peñaloza CL, Kendall WL, Solé G, Rodríguez-Clark KM (2015) Population trends and survival of nesting green sea turtles Chelonia mydas on Aves Island, Venezuela. Endang Species Res 29:103-116

* Garner JA, MacKenzie DS, Gatlin D (2017) Reproductive biology of Atlantic leatherback sea turtles at Sandy Point, St. Croix: the first 30 years. Chelonian Conserv Biol 16:29-43

*Hamilton RJ, Bird T, Gereniu C, Pita J and others (2015) Solomon Islands largest hawksbill turtle rookery shows signs of recovery after 150 years of excessive exploitation. PLOS ONE 10:e0121435

* Hawkes LA, Witt MJ, Broderick AC, Coker JW and others (2011) Home on the range: spatial ecology of loggerhead turtles in Atlantic waters of the USA. Divers Distrib 17: $624-640$

Heppell SS, Crouse DT, Crowder LB, Epperly SP and others (2005) A population model to estimate recovery time, population size, and management impacts on Kemp's ridley sea turtles. Chelonian Conserv Biol 4:767-773

IUCN (2017) Guidelines for using the IUCN Red List categories and criteria, v.13. Prepared by the Standards and Petitions Subcommittee. IUCN, Gland and Cambridge, www.iucnredlist.org/technical-documents/red-listdocuments

Jackson JBC, Kirby MX, Berger WH, Bjorndal KA and others (2001) Historical overfishing and the recent collapse of coastal ecosystems. Science 293:629-637

K Lauritsen AM, Dixon PM, Cacela D, Brost B and others (2017) Impact of the Deepwater Horizon oil spill on loggerhead turtle Caretta caretta nest densities in northwest Florida. Endang Species Res 33:83-93

* Luschi P, Hays GC, Papi F (2003) A review of long-distance movements by marine turtles, and the possible role of ocean currents. Oikos 103:293-302 
Marco A, Abella E, Liria-Loza A, Martins S and others (2012) Abundance and exploitation of loggerhead turtles nesting in Boa Vista island, Cape Verde: the only substantial rookery in the eastern Atlantic. Anim Conserv 15:351-360

Marcovaldi MÂ, Lopez GG, Soares LS, Lima EHSM, Thomé JCA, Almeida AP (2010) Satellite-tracking of female loggerhead turtles highlights fidelity behavior in northeastern Brazil. Endang Species Res 12:263-272

Mazaris AD, Matsinos G, Pantis JD (2009) Evaluating the impacts of coastal squeeze on sea turtle nesting. Ocean Coast Manage 52:139-145

Mazaris AD, Schofield G, Gkazinou C, Almpanidou V, Hays GC (2017) Global sea turtle conservation successes. Sci Adv 3:e1600730

Miller JD (1997) Reproduction in sea turtles. In: Lutz PL, Musick JA (eds) The biology of sea turtles. CRC Press, Boca Raton, FL, p 51-81

Mingozzi T, Mencacci R, Cerritelli G, Giunchi D, Luschi P (2016) Living between widely separated areas: long-term monitoring of Mediterranean loggerhead turtles sheds light on cryptic aspects of females spatial ecology. J Exp Mar Biol Ecol 485:8-17

National Marine Fisheries Service, U.S. Fish Wildlife Service (2008) Recovery plan for the northwest Atlantic population of the loggerhead sea turtle (Caretta caretta), 2nd Revision. National Marine Fisheries Service, Silver Spring, MD

Pfaller JB, Bjorndal KA, Chaloupka M, Williams KL, Frick MG, Bolten AB (2013) Accounting for imperfect detection is critical for inferring marine turtle nesting population trends. PLOS ONE 8:e62326

* Pfaller JB, Williams KL, Frick MG, Shamblin BM, Nairn CJ, Girondot M (2019) Genetic determination of tag loss dynamics in nesting loggerhead turtles: a new chapter in 'the tag loss problem'. Mar Biol 166:97

Phillips KF, Mansfield KL, Die DJ, Addison DS (2014) Survival and remigration probabilities for loggerhead turtles (Caretta caretta) nesting in the eastern Gulf of Mexico. Mar Biol 161:863

Piacenza SE, Balazs GH, Hargrove SK, Richards PM, Heppell SS (2016) Trends and variability in demographic indicators of a recovering population of green sea turtles Chelonia mydas. Endang Species Res 31:103-117

Piacenza SE, Richards PM, Heppell SS (2017) An agentbased model to evaluate recovery times and monitoring strategies to increase accuracy of sea turtle population assessments. Ecol Modell 358:25-39

R Development Core Team (2018) R: a language and environment for statistical computing. R Foundation for Statistical Computing, Vienna. www.r-project.org

Richards PM, Epperly SP, Heppell SS, King RT and others (2011) Sea turtle population estimates incorporating

Editorial responsibility: Matthew Godfrey, Beaufort, North Carolina, USA uncertainty: a new approach applied to western North Atlantic loggerheads Caretta caretta. Endang Species Res 15:151-158

Richardson JI, Bell R, Richardson TH (1999) Population ecology and demographic implications drawn from an 11year study of nesting hawksbill turtles, Eretmochelys imbricata, at Jumby Bay, Long Island, Antigua, West Indies. Chelonian Conserv Biol 3:244-250

Shamblin BM, Dodd MG, Griffin DBB, Pate SM and others (2017) Improved female abundance and reproductive parameter estimates through subpopulation-scale genetic capture-recapture of loggerhead turtles. Mar Biol 164:138

Spotila JRD, Leslie AE, Steyermark AJ, Plotkin AC, Paladino PT (1996) F.V. (1996) Worldwide population decline of Dermochelys coriacea: Are leatherback turtles going extinct? Chelonian Conserv Biol 2:209-222

Troëng S, Chaloupka M (2007) Variation in adult annual survival probability and remigration intervals of sea turtles. Mar Biol 151:1721-1730

Tucker AD (2010) Nest site fidelity and clutch frequency of loggerhead turtles are better elucidated by satellite telemetry than by nocturnal tagging efforts: implications for stock estimation. J Exp Mar Biol Ecol 383:48-55

*Wallace BP, DiMatteo AD, Hurley BJ, Finkbeiner EM and others (2010) Regional management units for marine turtles: a novel framework for prioritizing conservation and research across multiple scales. PLOS ONE 5:e15465

Wallace BP, Kot CY, Dimatteo AD, Lee T, Crowder LB, Lewison RL (2013a) Impacts of fisheries bycatch on marine turtle populations worldwide: toward conservation and research priorities. Ecosphere 4:40

Wallace BP, Tiwari M, Girondot M (2013b) Dermochelys coriacea. IUCN Red List of Threatened Species, v.2013.2, www.iucnredlist.org (12 December 2013)

W Wallace BP, Stacy BA, Rissing M, Cacela D and others (2017) Estimating sea turtle exposures to Deepwater Horizon oil. Endang Species Res 33:51-67

Warden ML, Haas HL, Richards PM, Rose KA, Hatch JM (2017) Monitoring trends in sea turtle populations: walk or fly? Endang Species Res 34:323-337

WWeber N, Weber SB, Godley BJ, Ellick J, Witt M, Broderick AC (2013) Telemetry as a tool for improving estimates of marine turtle abundance. Biol Conserv 167:90-96

*Witherington B, Kubilis P, Brost B, Meylan A (2009) Decreasing annual nest counts in a globally important loggerhead sea turtle population. Ecol Appl 19:30-54

Z Zbinden JA, Aebischer A, Margaritoulis D, Arlettaz R (2008) Important areas at sea for adult loggerhead sea turtles in the Mediterranean Sea: satellite tracking corroborates findings from potentially biased sources. Mar Biol 153: 899-906

Submitted: July 18, 2018; Accepted: December 2, 2019

Proofs received from author(s): January 24, 2020 